\title{
A TEORIA KANTIANA DO RESPEITO PELA LEI MORAL E DA DETERMINAÇÃO DA VONTADE
}

Julio ESTEVES ${ }^{1}$

- RESUMO: Este artigo tem por objetivo examinar uma tensão existente no interior da teoria kantiana do respeito pela lei moral. Originalmente, na Fundamentação, o respeito é concebido por Kant como um mero efeito ou subproduto da imediata determinação da vontade pela lei moral. Na segunda Crítica, contudo, Kant parece conceder um papel mais positivo ao respeito, dando a ele a tarefa de enfraquecer a influência exercida pelas inclinações, o que contaria como uma promoção da influência da lei moral sobre a vontade. Buscaremos mostrar que essa alteração na teoria kantiana do respeito é inteiramente devida a uma concessão a um difundido modelo de determinação da vontade que é de inspiração humiana. Além disso, buscaremos mostrar que esse modelo humiano tem de ser completamente abandonado, porque ele se choca tanto com a concepção refletida de Kant sobre motivação moral quanto com sua concepção refletida sobre a determinação da vontade pelas inclinações.

- PALAVRAS-CHAVE: vontade, lei moral, inclinações, respeito.

No interior de uma teoria moral em geral, há duas questões que têm de ser distinguidas entre si. De um lado, temos a questão sobre o critério de correção moral de uma ação, i.e., a pergunta pelo princípio de avaliação da conformidade de uma ação à moralidade. Dado, contudo, que a conformidade de uma ação às exigências da moralidade pode ser algo puramente contingente, temos, de outro lado, a pergunta pelo motivo unicamente capaz de levar à execução de ações dotadas de autêntico valor moral. Ora, a assim chamada moral sense theory acreditou poder responder a ambas as questões me-

1 Professor Associado na Universidade Estadual do Norte Fluminense Darcy Ribeiro e bolsista de produtividade em pesquisa do CNPq. Artigo recebido 08/2009 e aprovado em 11/2009. 
diante a introdução de uma espécie de sentimento, um suposto sentimento moral, que forneceria, simultaneamente, tanto um princípio de avaliação da correção moral de ações quanto um motivo para fazer o que a moral prescreve como correto.

Kant, por sua vez, rejeitou enfaticamente a moral sense theory. Pois, uma vez que sentimentos não passam de expressões contingentes das condições particulares de um sujeito, um juízo neles baseado não pode corresponder àquela pretensão de validade necessária e universal que ligamos com nossos juízos morais cotidianos. Eis por que Kant propôs-se buscar em outra parte, a saber, na razão prática, o que ele chamou de principium diiudicationis, a instância de avaliação da correção moral das ações. Ora, a resposta kantiana a essa primeira questão trouxe consequências para a segunda questão. Pois Kant deu-se conta de que certas ações podem até estar em conformidade externa com nossos critérios de correção moral, embora tenham sido feitas por motivos indiferentes ou mesmo contrários à moralidade, o que lhes retira completamente qualquer pretensão de valor moral autêntico. Desse modo, para possuir autêntico valor moral, não é suficiente que a ação esteja conforme ao que prescreve o critério de avaliação. Em última análise, é preciso que o próprio motivo da ação esteja também conforme às exigências postas pelo critério de avaliação. Ora, o critério de avaliação moral exige de uma ação que ela possa figurar na legislação moral, ou seja, que tenha validade necessária e universal, e, por conseguinte, o mesmo vale para o próprio motivo da ação, caso ela deva possuir autêntico valor moral. Eis por que Kant veio a sustentar a tese forte segundo a qual ações com autêntico valor moral são aquelas passíveis de fundamentação última, ou seja, são aquelas cujos motivos ou princípios possuem a validade universal e necessária da própria lei moral. ${ }^{2}$ Assim sendo, Kant teve de excluir de sua teoria da motivação moral qualquer elemento de ordem subjetiva, como um sentimento moral, por exemplo, já que, em última análise, isso comprometeria a validade necessária e universal da ação. Argumentando, porém, com base em premissas diametralmente opostas às da moral sense theory, Kant foi levado a uma conclusão formalmente semelhante, a saber, à conclusão de que a lei moral tem de servir, simultaneamente, como critério e como motivo de ações morais autênticas, ou, em termos kantianos, de que

2 Isso precisa ser qualificado. Pois uma ação pode ter valor moral mesmo que não tenha tido por motivo exclusivo a mera consciência da sua conformidade à lei moral, por exemplo, uma ação cujo fim é a satisfação de uma inclinação, porém, desde que o agente tenha submetido a máxima que a preside ao crivo da lei moral e verificado que o curso de ação correspondente não é moralmente proibido, mas, sim, permitido. Assim, a tese mencionada diz respeito exclusivamente às ações moralmente obrigatórias 
o principium diiudicationis tem de servir, simultaneamente, como o principium executionis de tais ações. ${ }^{3}$

Desse modo, a teoria moral kantiana exige que a mera consciência de que um curso de ação é exigido pela lei da razão pura prática seja o exclusivo motivo de ações morais (obrigatórias). A teoria da ação, ou melhor, uma teoria da ação de orientação humiana, pode, entretanto, sustentar que razões enquanto tais, sobretudo puras razões morais tais como concebidas por Kant, não têm poder de motivar-nos para a execução de ações, pois somente sentimentos, emoções ou afetos teriam tal força motivacional. E, de fato, a teoria humiana da ação parece não ser nada além de uma simples expressão de uma trivialidade cotidianamente constatável. Pois eu posso compreender claramente que tenho muito boas razões para fazer uma dieta, mas, como escreve Tugendhat (1993, p. 25), "permanecer completamente frio" diante dessas razões, até o momento em que começo a desejar emagrecer para chamar a atenção de alguém. Ora, diante dessa teoria da ação, cuja correção seria facilmente constatável, mesmo pelo senso comum, a teoria da motivação moral kantiana parece representar uma mera construção filosófica fundada em premissas metafísicas, como sugeriu muitas vezes Tugendhat (1987, pp. 48-9).

Ou será que haveria também aqui, na filosofia prática, uma "alternativa negligenciada" por Kant, análoga àquela concernente à tese da não espacio temporalidade das coisas em si, defendida na filosofia teórica? Pois talvez fosse possível continuar sustentando, de um lado, que a mera consciência da validade universal e necessária da máxima seja a fonte exclusiva de valor moral autêntico de uma ação, admitindo-se, de outro lado, que algo de natureza propriamente sensível ou afetiva seja o motivo ou móvel da ação moral, contanto que esse móvel sensível não resultasse da constituição subjetiva particular de cada agente, mas, antes, da própria consciência da lei. Essa alternativa representaria uma síntese das exigências feitas pela teoria moral kantiana, de um lado, e das exigências feitas pela teoria da ação humiana, de outro, o que aparentemente faria com que a primeira ganhasse muito em plausibilidade.

$\mathrm{Na}$ verdade, que Kant não tenha negligenciado essa alternativa, fica claro na oscilação do valor posicional conferido ao sentimento do respeito no interior de sua teoria moral. Pois, em sua primeira referência a esse sentimento na primeira seção da Fundamentação da metafísica dos costumes (GMS, 401-2), afirma que o respeito não passa de um efeito ou, por assim

3 Em suas lições sobre ética, ainda na fase pré-crítica, Kant já havia introduzido a distinção entre o "Principium der Dijudikation der Verbindlichkeit" e o "Principium der Exekution oder Leistung der Verbindlichkeit" (Kant, 1991, p. 46 e segs.). 
dizer, um subproduto da imediata determinação da vontade pela lei moral, a mera consciência da lei sendo apresentada como o exclusivo motivo da ação moral. Em algumas passagens da Crítica da razão prática, contudo, Kant sustenta que esse sentimento seria o Triebfeder, ou móvel, para a execução de ações morais, na medida em que "limitaria a influência das inclinações" (KpV, A 133). Ora, essa oscilação do valor posicional do sentimento do respeito na teoria moral corresponde e é paralela a uma oscilação na consideração do modelo de determinação da vontade que subjaz à teoria kantiana da ação. Na verdade, um desses modelos de determinação da vontade, o modelo humiano, é completamente estranho à posição refletida de Kant a respeito da determinação da vontade pela lei moral e, mais que isso, completamente incompatível com a especificidade da teoria da motivação em geral que pode ser depreendida de algumas passagens de suas obras. Assim, no que segue, defenderei a tese segundo a qual o respeito não pode ter nenhuma função motivadora ou propulsora para ações com valor moral. Buscarei mostrar também que a tentativa de conferir função motivadora ou propulsora a esse sentimento feita por Kant e por alguns de seus intérpretes, como, por exemplo, Harald Köhl, discípulo de Tugendhat, funda-se na aceitação inquestionada da premissa da teoria da ação humiana, segundo a qual somente sentimentos ou emoções podem conferir força motivacional a frias razões em geral, e, por conseguinte, somente um sentimento especificamente moral seria capaz disso no caso das razões morais (cf. Köhl, 1990).

É preciso, entretanto, ter antes alguma clareza sobre os sentidos que pode assumir a expressão "respeito" numa teoria moral. Em primeiro lugar, "respeito" pode significar uma atitude ou disposição no sentido de agir sempre levando em consideração os demais. Nesse caso, o respeito não é um sentimento, mas uma atitude ou comportamento que a lei moral, interpretada no sentido da regra de ouro, exige que todos os seres humanos observem uns com relação aos outros. Kant tematiza o respeito tomado nesse sentido sobretudo na Metafísica dos costumes, mas as sólidas bases para seu tratamento já haviam sido lançadas na Fundamentação, mais exatamente, na fórmula do imperativo categórico que exige dos seres racionais tratarem-se reciprocamente como fins em si mesmos.

Em segundo lugar, "respeito" pode ser tomado como expressão de nossa admiração na avaliação dos feitos e capacidades ou talentos de alguém, a saber, como professor, como artista, como atleta, etc., ou, no caso específico da moral, simplesmente como pessoa. Neste último caso, dizemos que a pessoa exemplifica de modo notável aquelas propriedades que a lei moral espera de todos nós. Diferentemente do respeito tomado como atitude diante dos outros, que um agente simplesmente observa ou não, o respeito relacionado ao valor de uma pessoa admite diferentes graus em nossa avaliação. Do mesmo modo, o respeito como atitude tem um oposto contraditório, 
a saber, simplesmente a ausência ou falta de respeito, ao passo que o oposto do respeito ligado ao valor de uma pessoa é seu contrário, a saber, o desprezo pela pessoa. Kant faz menção ao respeito tomado nesse sentido, na Fundamentação, mostrando que ele também depende da lei moral. Pois "todo respeito por uma pessoa é propriamente somente respeito pela lei [...], da qual aquela pessoa nos dá o exemplo" (GMS, 401-2).

Por fim, há o respeito como sentimento moral. Na teoria moral kantiana, o respeito tomado nesse sentido também só pode ser compreendido à luz da lei moral. Ou seja, diferentemente da moral sense theory, Kant sustenta que esse sentimento não antecede logicamente à consciência das exigências feitas pela lei moral. Resta, porém, ainda por determinar se ele pode ter alguma função como motivo propulsor de ações morais. ${ }^{4}$

Kant introduz a discussão sobre o respeito, na Fundamentação, acentuando que não se trata de um sentimento resultante da constituição particular do sujeito, mas de um sentimento peculiar produzido por um conceito da razão. Como tal, ele não precede à consciência da lei, e, por conseguinte, não se pode atribuir a ele a função de informar o sujeito sobre o que exige a moralidade nem para determiná-lo a cumprir o que ela ordena. Pois, segundo Kant (GMS, 401-2),

o que conheço imediatamente como lei para mim, conheço com respeito, que significa simplesmente a consciência da subordinação da minha vontade a uma lei, sem mediação de outras influências sobre o meu sentido. A determinação imediata da vontade pela lei e a consciência dessa determinação se chama respeito, de modo que este deve ser considerado como efeito da lei sobre o sujeito, e não como causa desta.

Assim, o respeito não passa de um efeito da determinação da vontade pela lei, de um efeito, porém, cuja ocorrência e natureza pode ser conhecida a priori. Pois, do mesmo modo que podemos saber a priori que a lei moral tem de ser representada por um ser racional finito como um dever incondicional, como um imperativo categórico, é igualmente possível saber a priori

4 Como observa Allison (1991, pp. 126-7), a teoria kantiana do respeito pode ser considerada como parte de uma espécie de "fenomenologia moral", como uma descrição dos efeitos psicológicos da consciência da lei moral sobre nossa sensibilidade. Ora, isso nos faz lembrar imediatamente de "Freedom and Resentment", de Strawson (2008, pp. 1-28), no qual uma descrição igualmente fenomenológica revela não apenas um, como em Kant, mas uma rede de sentimentos e atitudes conectados entre si e com determinados juízos. De fato, é uma questão importante, mas que será deixada intocada aqui, saber se é possível resgatar a pretensão de unicidade do sentimento do respeito explicitamente erguida por Kant. Para tal, seria preciso pelo menos mostrar que a multiplicidade de sentimentos morais, como vergonha, culpa, indignação, arrependimento, etc., só pode ser compreendida a partir do respeito como sentimento moral primitivo. 
que a consciência da determinação pela lei terá um determinado efeito sobre sua sensibilidade. Pois, embora não se possa supor a presença de alguma inclinação ou tendência natural para a moralidade no ser racional finito, podemos supor nele a existência de tendências ou inclinações contrárias à lei moral. Desse modo, pelo fato de o ser racional finito dispor de outros princípios de determinação que não os racionais, podemos atribuir-lhe, por princípio, uma discrepância entre o que ele quer e o que a razão pura prática lhe prescreve. Por conseguinte, podemos saber a priori que a lei terá de constranger os princípios de determinação contrários, a saber, as inclinações, quando da determinação da vontade. Ora, prossegue Kant em outra passagem, "toda inclinação e todo impulso sensível está fundado sobre o sentimento, e o efeito negativo sobre o sentimento (pelo dano que acontece às inclinações) é ele mesmo sentimento" (KpV, A 129).

Desse modo, pelo fato de a lei causar dano às inclinações, o efeito desta sobre a faculdade de apetição será negativo, algo análogo ao sentimento de dor ou aversão. Mas a determinação da vontade pela lei apresentará também, segundo Kant, um momento positivo. Pois a determinação da vontade é acompanhada pelo reconhecimento de que a lei representa um valor mais alto do que as inclinações, enquanto princípios de determinação concorrentes, pois o agente reconhece essa lei como algo que ele impõe a si próprio como um produto de sua autonomia. Eis por que, ainda na Fundamentação, Kant afirma que, nessa perspectiva, o respeito apresenta uma analogia como a inclinação ou prazer. Assim, em última análise, o respeito pela lei implica o respeito do agente racional moral por si mesmo. Na medida em que, por seu valor, a lei moral se apresenta, porém, como um "objeto do maior respeito" (KpV, A 130), ela humilha todas as pretensões das inclinações, produzindo um sentimento de aversão pelas últimas. Eis por que Kant reúne esses diferentes momentos do sentimento moral sob o nome do respeito (devido ao valor da lei), que ele diz ser "o único que conhecemos plenamente a priori e cuja necessidade podemos discernir" (KpV, A 130; cf. também A 133).

Em suma, o respeito é inicialmente concebido por Kant como um efeito ou subproduto da determinação da vontade pela lei moral, e, por conseguinte, não pode ser o móvel para ações morais ou motivar a vontade a se determinar moralmente. Pois, quando o respeito aparece, a vontade já se determinou moralmente, ou seja, já reconheceu a validade da lei moral e subordinou-se a ela. O respeito nada mais é que o lado sensível da consciência da imediata determinação da vontade pela lei moral.

Em outras passagens do terceiro capítulo da segunda Crítica, Kant, contudo, parece dar a entender que o sentimento do respeito não é um mero resultado ou efeito da consciência do valor da lei diante das inclinações contrárias, concedendo-lhe então um papel mais positivo, o papel de 
móvel moral, de Triebfeder para a moralidade. Assim, Kant afirma, por exemplo, que "a lei moral [...] é princípio de determinação subjetivo, i.e., móvel para esta ação, ao ter influência sobre a sensibilidade do sujeito e ao produzir um sentimento que é favorável à influência da lei sobre a vontade" (KpV, A 133-4; cf. também A 135). Em outra passagem, Kant explica por que passou a considerar agora o sentimento do respeito como um Triebfeder, como um móvel para a moralidade. Pois o respeito favoreceria a influência da lei sobre a vontade humana, na medida em que se oporia aos obstáculos representados pelas inclinações, e "toda redução de obstáculos a uma atividade é promoção dessa mesma atividade" (KpV, A 140). Em suma, o respeito teria um papel positivo na determinação da vontade pela lei, porque ele se constituiria como negação da negação representada pelas inclinações contrárias à moralidade.

Temos de admitir, contudo, que essa tentativa de converter o respeito num móvel para a moralidade incorre numa contradição com as próprias declarações feitas por Kant. Pois, se o sentimento do respeito não precede à determinação da vontade pela lei, sendo antes vivenciado pelo sujeito por ocasião dessa determinação, então o respeito não pode ser o responsável pela limitação da influência das inclinações. Pelo contrário, ele é justamente o resultado da limitação das inclinações no momento em que a vontade, reconhecendo o valor da lei moral, faz dela uma máxima para si, humilhando as pretensões das inclinações. Assim, já que é a vivência que se tem quando as inclinações são enfraquecidas por um valor mais alto superior, o respeito pressupõe que as inclinações já tenham sido enfraquecidas. ${ }^{5}$

A doutrina do respeito como móvel para a moralidade representa uma falta de clareza por parte de Kant acerca das peculiaridades de sua própria teoria da motivação e, além disso, uma concessão indevida à teoria humiana da motivação. Com efeito, a linha de raciocínio adotada por Kant parece ter sido a seguinte. Se a lei moral, enquanto um princípio de determinação proveniente da razão pura prática, deve exercer uma influência limitadora sobre princípios de determinação tão heterogêneos com relação a ela, como o são as inclinações, é preciso que haja, por assim dizer, uma arena comum em que tal influência possa exercer-se. Ora, num determinado momento, Kant parece ter pensado que este terreno comum, no que respeita ao ser racional finito, só poderia ser a sensibilidade. Assim, o reconhecimento da lei moral produziria o sentimento do respeito, o qual, por sua vez, neutralizaria os móveis não-morais opostos, permitindo que a lei moral torne-se prática e efetiva em nós. Ora, como observa Andrews Reath, "a necessidade de um

5 Cf., a esse respeito Reath (1989, p. 288). 
tal modelo poderia estar baseada na suposição de que os obstáculos afetivos postos pelas inclinações só possam ser controlados por uma força afetiva maior". ${ }^{6}$ Assim, a doutrina do respeito como móvel para a moralidade implica um comprometimento por parte de Kant com uma teoria da determinação da vontade baseada no modelo de vetores de forças: o indivíduo agiria ou não moralmente em cada caso, na medida em que o sentimento moral fosse ou não mais forte que os sentimentos contrários. Mas, de fato, tal modelo é completamente incompatível com os propósitos de Kant, a saber, com a sua pretensão de mostrar que a razão pura, sem pressuposição de qualquer sentimento, pode fornecer um princípio de determinação suficiente da vontade, o que tornaria a última diretamente responsável pela ação moral. Pois, em contraposição a isso, aquele modelo tornaria impossível a imputabilidade de ações contrárias à moral, uma vez que a força ou intensidade do sentimento do respeito não seria algo que dependeria da vontade do indivíduo, mas da sua natureza ou constituição particular. Por fim, como foi dito, essa doutrina do respeito como móvel representa uma inconsistência interna no texto de Kant, já que o respeito é o resultado da neutralização promovida pelo reconhecimento da lei moral, não podendo ter, portanto, a função de neutralização das inclinações. Por tudo isso, essa doutrina deve ser rejeitada como interpretação oficial do valor posicional e da função do respeito, em Kant.

Após ter mostrado que esse modelo de determinação da vontade segundo vetores de forças afetivas contrapostas não é compatível com os objetivos de Kant, Reath passa para sua proposta de solução do problema, que pode ser assim resumida. Para que haja uma influência limitadora por parte da lei moral sobre as inclinações, enquanto princípios de determinação tão heterogêneos entre si, é preciso que elas se encontrem num terreno comum. Dado que esse terreno comum não pode ser o de uma sensibilidade caracterizada por forças afetivas contrapostas; dado que a mera consciência da lei moral deve exercer imediatamente tal influência limitadora sobre as inclinações, então só nos resta buscar esse terreno comum naquilo que caracteriza a própria consciência da lei moral. Ora, vimos acima que a consciência da lei inclui também um momento positivo, mais exatamente, quando do reconhecimento por parte do agente de que a lei moral que sua vontade impõe a si própria possui um valor mais alto do que podem pretender as inclinações dadas, o que faz com que ela seja, por isso mesmo, "objeto do maior respeito". Desse modo, a limitação que a lei moral exerce sobre as inclinações não decorre de uma força afetiva contrária que aquela

6 Cf. Reath (1989, p. 289). 
produz sobre as últimas, e sim do reconhecimento de seu valor mais alto. Mas isso quer dizer, então, que, ainda que se possa admitir que as inclinações tenham uma força afetiva, não é por tal força afetiva que elas influenciam a vontade, mas sim pelo valor que o agente supõe que elas tenham e que é limitado quando confrontado com o da lei moral. De outro modo, não seria possível explicar a influência limitadora da lei moral, a qual não exerce qualquer força afetiva.

Entretanto, Harald Köhl sustenta que o respeito é, de fato, o móvel propulsor para ações morais, resumidamente, da seguinte maneira. Apesar de reconhecer que é o efeito da lei moral, Köhl ainda assim afirma que, pelo fato de implicar no sujeito também o respeito por si mesmo enquanto autor da lei a que está submetido, o respeito produziria uma espécie de "inclinação para nós mesmos", uma inclinação para realizarmos ações que são conformes à nossa destinação (Bestimmung) e dignidade de seres autolegisladores. Mas, prossegue Köhl (1990, p. 136),

se a consciência da lei [...] faz com que essa lei nos apareça como objeto de uma inclinação, a qual tem por objeto aquilo que essencialmente somos enquanto seres humanos: então torna-se evidente por que Kant pôde considerar o sentimento produzido por meio disso como sendo o Triebfeder moral em geral. De acordo com isso, o respeito pela lei seria a fonte de motivação afetiva para o agir moral em geral.

Deve-se notar que Köhl tem clareza sobre o fato de que o respeito não é o móvel para assumir o ponto de vista moral, pois seu surgimento supõe a prévia assunção desse ponto de vista. ${ }^{7}$ Ele sustenta antes que ele é o móvel para executar ações morais, pois, como bom discípulo de Tugendhat, ele supõe que a mera e fria consciência da validade da lei não é capaz de impulsionar a nós homens, feitos de "uma madeira tão torta", para a execução de ações morais.

Contra a interpretação por Köhl, além do que foi dito anteriormente, gostaria apenas de acrescentar aqui que ele leva longe demais o que, para Kant, não passa de uma analogia entre o respeito e a inclinação, analogia que, a meu ver, está fundada no simples fato de estarem ambos relacionados à sensibilidade, e não no fato de exercerem igualmente uma força afetiva. Como quer que seja, na discussão sobre o valor posicional do respeito e sua relação com as inclinações, o decisivo é ter clareza sobre o modo pelo qual as últimas influenciam a vontade. Pois as tentativas feitas por Kant e acatadas por alguns intérpretes no sentido de conferir ao respeito a função de motivador ou propulsor para ações morais devem-se à disseminada in-

7 Cf. Köhl (1990, p. 136). 
fluência exercida pelo que estou chamando de premissa da teoria humiana da ação, segundo a qual algo de natureza puramente intelectual, como a mera consciência da validade de uma lei, é incapaz de nos mover ou impulsionar para ações em conformidade, o que exigiria a introdução de algum componente conativo de natureza emocional ou afetiva. Ora, até aqui, nossa exposição desenvolveu-se apenas no interior da teoria moral kantiana. Ou seja, vimos que, se a razão pura deve ser prática e, como pretende Kant, exercer uma influência limitadora sobre as inclinações, então só nos resta admitir que estas, por sua vez, influenciam a vontade, na medida em que se apresentam ou são tomadas pelo agente como possuindo um certo valor, que é menosprezado tão logo haja comparação com a lei moral. Precisamos, contudo, fazer agora o caminho inverso, ou seja, para usar a conhecida expressão kantiana, "von unten auf", ou seja, "de baixo para cima", partindo do modo pelo qual as inclinações afetam a vontade, para chegar então à lei moral. Assim sendo, buscaremos mostrar contra a teoria humiana da ação que, independentemente das exigências da teoria moral kantiana, as inclinações só influenciam a vontade do ser racional finito, em virtude do valor que o agente supõe que elas tenham, e não por sua força afetiva.

Como um primeiro passo nesse sentido, gostaria de recorrer à seguinte conhecida passagem da primeira Crítica (KrV, B 131-2).

O: "eu penso" tem de poder acompanhar todas as minhas representações; pois, do contrário, seria representado algo em mim que não poderia de modo algum ser pensado, o que equivale a dizer ou que a representação seria impossível, ou que não seria nada pelo menos para mim.

Segundo Kant, é bem possível que eu tenha muitas representações em mim, das quais não tenho consciência, pois o conceito de representação não contém em si nenhuma referência necessária a uma consciência (KrV, B 376). Se deve ser, contudo, possível ter consciência de uma representação, então o "eu penso" tem de poder acompanhá-la. Ora, essa possibilidade necessária de acompanhamento pelo "eu penso" significa ao menos que a representação, caso deva ser consciente, tem de poder ser pensada, tem de poder ser acompanhada por um conceito. Pois, do contrário, estaríamos diante das seguintes alternativas: ou bem a representação seria impossível, pois seu próprio conceito seria logicamente impossível, ou bem, mesmo supondo que ela fosse objeto de um conceito possível, ela não seria nada (de determinado) pelo menos para mim, pois eu não disporia de um conceito para descrever tal representação. ${ }^{8}$ Ora, conceitos são nada além de predi-

8 Cf. Esteves (1996, pp. 21-2). 
cados de juízos ou proposições possíveis (KrV, A 69/B 94). Donde, a consciência de representações em mim é uma consciência proposicional.

Analogamente, é bem possível que eu tenha muitas inclinações em mim, das quais não tenho consciência. Pois o conceito de inclinação não contém em si nenhuma referência necessária a uma consciência. Se deve ser, contudo, possível ter consciência de uma inclinação, então o "eu penso" tem de poder acompanhá-la, ela tem de poder ser acompanhada por um conceito. Assim, inclinações conscientes têm de encontrar expressão em juízos ou proposições. Na verdade, é nisso que Kant vê residir a diferença entre a vontade humana e a faculdade de apetição nos animais. Com feito, nos animais, os móveis consistem em inclinações ou impulsos cegos, mas, nos homens, as inclinações recebem uma formulação conceitual, i.e. proposicional, e se convertem num interesse (GMS, 414).

Ora, já que com a consciência de uma proposição está necessariamente ligada a consciência da possibilidade de negação dessa proposição, então com a consciência de uma inclinação enquanto um princípio de determinação possível da vontade, i.e., com a consciência da possibilidade de executar uma ação em resposta a uma inclinação, está necessariamente ligada a consciência da possibilidade da omissão da ação, por mais que a inclinação tenha força afetiva. Desse modo, o ser racional finito não é diretamente determinado à ação por um móvel qualquer, diferentemente "das criaturas irracionais (que) apenas sentem impulsos sensíveis" (GMS, 460), mas encontra diante de si um âmbito de possibilidades de ação alternativas, em relação às quais tem de refletir com vistas a uma escolha.

Toda reflexão é orientada por uma pergunta. A pergunta que preside especificamente essa reflexão diante de possibilidades de ação alternativas é a seguinte: o que é bom, conforme o caso, melhor, que eu faça? Ou seja, a execução de uma ação em resposta a uma inclinação, se for o caso, a adoção de uma inclinação enquanto um princípio de determinação da vontade envolve a possibilidade de o agente considerá-la como boa em algum sentido e em alguma medida. Ora, por sua vez, a palavra "bom" designa justamente uma preferência entre possibilidades alternativas, para a qual se ergue uma pretensão de fundamentação, i.e., para a qual se ergue a pretensão de ser possível aduzir razões. Eis por que podemos também dizer que as inclinações só são admitidas enquanto princípios de determinação da vontade, na medida em que o agente pode encará-las como sendo ou fornecendo razões suficientes para agir. Desse modo, se, como foi dito acima a respeito da trivialidade da teoria humiana da ação, a mera consciência de que tenho boas razões para emagrecer só se torna efetiva em minhas ações, na medida em que passo a desejar isso, o próprio desejo de emagrecer tem de poder ser, por sua vez, encarado por mim como uma boa razão para agir. 
Ora, aquilo que foi considerado como uma razão numa dada situação tem também de valer, segundo o próprio sentido de "razão", para todos os casos que se assemelhem em seus aspectos relevantes. Assim, uma vez que as inclinações só são acolhidas pela vontade, na medida em que são encaradas como razões suficientes para agir, então a adoção de uma inclinação enquanto princípio de determinação da vontade acarretará uma pretensão de validade para todos os casos que se assemelhem em seus aspectos relevantes, i.e., a pretensão de que quem quer que se encontre na mesma situação terá de encará-la igualmente como uma razão suficiente para agir. Ou seja, as inclinações determinam as escolhas, na medida em que são consideradas pelo agente como fontes de razões que podem ser citadas de alguma forma, de modo que suas ações tornem-se aceitáveis aos olhos dos outros. Numa palavra, a escolha de inclinações como princípios de determinação da vontade ocorre em bases quasi-morais. ${ }^{9}$

Se as inclinações influenciam a vontade, na medida em que são tomadas pelo agente como algo que tem um determinado valor, como sendo de algum modo boas e fornecendo razões suficientes para agir, podemos compreender o modo pelo qual a lei moral pode exercer uma influência limitadora sobre elas. A lei moral simplesmente humilha as pretensões de valor ou de força justificatória porventura erguidas pelo agente para suas inclinações, apresentando-se como autêntica razão última justificadora e como valor supremo. ${ }^{10} \mathrm{E}$, como foi visto, é nesse momento que o respeito surge como resultado da consciência dessa humilhação.

Desde "Ética moderna e ética antiga", seu primeiro livro sobre ética, Ernst Tugendhat vem reiteradamente tecendo críticas à teoria moral kantiana, não tanto no que tange ao principium diiudicationis, mas ao principium executionis proposto por Kant. Segundo Tugendhat, Kant só pôde chegar à sua concepção de razão pura prática, segundo a qual a racionali-

9 Nesse ponto, acompanho Reath em uma de duas qualificações que ele julga indispensáveis. Em primeiro lugar, as inclinações não precisam fornecer de fato boas razões, para serem admitidas como motivos; basta apenas que o agente de fato assim as considere, numa palavra, o agente pode se dar por satisfeito com o que aos olhos de terceiros não passam de racionalizações. Em segundo lugar, também não é necessário que o agente considere que suas inclinações, enquanto razões para agir, são aceitáveis do ponto de vista de todos, i.e. do ponto de vista da universalidade em sentido estrito; basta apenas que o agente possa considerá-las como aceitáveis aos olhos de sua comunidade mais imediata (cf. Reath, 1989, p. 296). Contudo, com relação à segunda qualificação, poder-se-ia objetar que o agente só considera como suficiente a aceitabilidade por parte de sua comunidade mais imediata, porque ele próprio considera aceitáveis, ou seja, universalmente defensáveis, os princípios que regulam as avaliações dessa comunidade.

10 Assim, a crítica kantiana do princípio da felicidade ou do amor-de-si, enquanto princípio sob o qual as inclinações são reunidas, vai justamente no sentido de mostrar que ele não é capaz de resgatar as pretensões valorativas que são ordinariamente erguidas com ele e que foram erguidas também por grande parte da tradição filosófica. 
dade do moralmente ordenado seria o próprio motivo da ação genuinamente moral, tendo por base determinadas premissas metafísicas destinadas a dividir a personalidade do agente em dois estratos, um sensível e outro inteligível, a motivação especificamente moral sendo atribuída ao lado inteligível. ${ }^{11}$ Ora, uma vez que a metafísica não encontra mais força de convicção entre nós, só restaria como alternativa ou bem renunciar ao agir genuinamente moral, ou bem fundá-lo numa motivação empírica qualquer. De acordo com isso, Tugendhat procura reinserir a questão da felicidade no interior da moralidade, defendendo então a tese, segundo ele, "coberta com escárnio por Kant", de que "só somos realmente felizes quando agimos moralmente", de modo que a busca da felicidade converter-se-ia no motivo do agir moral propriamente dito (Tugendhat, 1987, p. 50).

Contra a crítica de Tugendhat, no que respeita à motivação moral, podemos agora utilizar os elementos da teoria kantiana da motivação em geral. Se é verdade que as inclinações só influenciam a vontade e são adotadas como motivos, sob a condição de poder ser encaradas pelo agente como razões com força justificatória, então será possível dar plausibilidade à exigência de que a racionalidade do moralmente ordenado seja o motivo do agir genuinamente moral, sem precisar lançar mão de premissas metafísicas ou de algum elemento conativo de ordem afetiva, como o próprio Kant acabou tentando fazer com o sentimento de respeito. Pois, se o ser racional finito não pode agir senão sob o pressuposto de que mesmo seus princípios de determinação empiricamente fundados são aceitáveis do ponto de vista dos demais, i.e., sob o pressuposto de que têm força justificatória, então será possível mostrar que essa mera capacidade de aceitabilidade pelos demais pode ser o motivo das ações especificamente morais. Pois, se é verdade que mesmo inclinações sensíveis são acolhidas como motivos não unicamente em virtude do prazer que prometem, se o acolhimento das inclinações enquanto princípios de determinação é também orientado pelo princípio da possibilidade de justificação, então é possível mostrar que o mero fato de um princípio não passar pelo teste da universalização, i.e., pelo teste da justificação, é uma razão suficiente para omitir a ação correspondente e fazer o oposto. Em suma, se o ser racional finito, enquanto um composto de razão e sensibilidade, não pode agir senão sob o pressuposto de que os princípios de suas ações satisfazem ao princípio da racionalidade, será possível defender a tese de que o mero princípio da racionalidade possa ser para ele princípio, ou melhor, motivo de suas ações.

Não basta, contudo, mostrar que há plausibilidade na tese kantiana de que o princípio da racionalidade pode servir como motivo das ações de um

11 Op. cit., p.49. 
ser racional finito. É preciso que se mostre, além disso, o modo pelo qual ele pode converter-se realmente num motivo. Pois, do ponto de vista do ser racional finito, a lei moral é apenas um entre uma pluralidade de princípios de determinação possíveis. Desse modo, para que seja acolhida como motivo das ações, é preciso que a lei moral possa ser encarada pelo ser racional finito como sendo boa, e, na verdade, como tendo um valor que a situa acima de tudo o que as inclinações possam prometer enquanto princípios de determinação. Em suma, se a lei moral deve ser acolhida como máxima de um ser racional finito, é preciso que desperte um interesse, em que "interesse" não designa sentimento algum, e sim somente o fato de ela poder ser encarada como boa em algum sentido específico. Ora, a explicação a respeito do modo pelo qual a lei moral pode interessar, ou seja, da razão para adotar-se a lei moral como princípio de ação, estaria no fato de ela ser a condição da racionalidade na escolha dos fins. A lei moral exprimiria um critério de seleção dos fins postos pelas inclinações que seriam compatíveis com a vontade de um ser racional em geral, vale dizer, com a autonomia da vontade de um agente, na medida em que põe para si mesmo os fins de suas ações. Desse modo, a razão para adotar a lei como máxima residiria no fato de ela exprimir a condição de ser sujeito dos fins, i.e., de propor-se livremente os fins de suas ações, e isso é algo que o ser racional finito não pode, racionalmente falando, não querer, ou seja, é algo que tem de estar no seu maior interesse.

ESTEVES, Julio. Kant's theory of respect for the moral law of the determination of the will. Trans/Form/Ação. São Paulo, v.32(2), 2009, p.75-89.

- ABSTRACT: This paper intends to examine a tension within Kant's theory of respect for the moral law. Originally, in the Groundwork, respect is conceived by Kant as a mere effect or by-product of the immediate determination of the will by the moral law. However, in the Second Critique, Kant seems to confer to respect a more positive role by assigning to it the task to weaken the influence exercised by the inclinations, thereby promoting the influence of the moral law on the will. We show that this shift in Kant's theory of respect is entirely due to a concession to a widespread model of determination of the will by inclinations, which is of Humean inspiration. Besides, we show that that Humean model must be completely abandoned because it is at odds both with Kant's considered view of moral motivation and of the determination of the will by inclinations.

- KEYWORDS: will, moral law, inclinations, respect. 


\section{Referências bibliográficas}

ALLISON, H. Kant's Theory of Freedom. Nova York: Cambridge University Press, 1991.

ESTEVES, J. "A dedução transcendental no § 16 da Crítica da razão pura". Síntese Nova Fase, Belo Horizonte, v. 23, n. 722, 1996, pp. 13-36.

KANT, I. Kritik der reinen Vernunft. Hamburgo: Felix Meiner, 1976.

. Grundlegung zur Metaphysik der Sitten. Stuttgart: Philipp Reclam, 1984.

. Eine Vorlesung über Ethik. Nova ed. por G. Gerhardt. Frankfurt am Main: Fischer, 1990. 2002.

KÖHL, H. Kants Gesinnungsethik. Berlim: Walter de Gruyter, 1990.

REATH, A. "Kant's Theory of Moral Sensibility: Respect for the Moral Law and the Influence of Inclination". Kant-Studien, 80, 1989, pp. 284-302.

STRAWSON, P.F. "Freedom and Resentment". In: Freedom and Resentment and other Essays. Londres/NovaYork: Routledge, 2008, pp. 1-28.

TUGENDHAT, E. "Antike und moderne Ethik". In: Probleme der Ethik. Stuttgart: Philipp Reclam, 1987.

. Vorlesungen über Ethik. Frankfurt am Main: Suhrkamp, 1993. 